\title{
Aggregation Behaviour of Sodium Cholate and Sodium Deoxycholate Under the Influence of Drug (Disprine) in Aqueous Solution at Various Temperatures
}

\author{
Shweta Singh ${ }^{1}$, Santosh K. Sar ${ }^{1, ~ *, ~ T o n m o y ~}$ Ray $^{2}$ \\ ${ }^{1}$ Department of Applied Chemistry, Bhilai Institute of Technology, Durg, (C.G.) India \\ ${ }^{2}$ Department of Biotechnology, National Institute of Technology, Durgapur, (W.B.) India
}

Email address:

Santoshsar@hotmail.com (S. K. Sar)

*Corresponding author

\section{To cite this article:}

Shweta Singh, Santosh K. Sar, Tonmoy Ray. Aggregation Behaviour of Sodium Cholate and Sodium Deoxycholate Under the Influence of Drug (Disprine) in Aqueous Solution at Various Temperatures. Science Research. Vol. 4, No. 5, 2016, pp. 112-119. doi: 10.11648/j.sr.20160405.12

Received: September 22, 2016; Accepted: October 21, 2016; Published: November 25, 2016

\begin{abstract}
To get accurate concentration of drug in systemic way for pharmacological response, Solubility is an important parameter to be shown. Most of the newly discovered chemical entities of the drugs are subjected to lipid lover (lipophile) due to this it carries the properties of poor water solubility. That's why solubility behavior is one of the most important for formational developments [24, 25]. Colloidal drug has to be in desired properties for the development of drug carrier, it is essential to examine physico-chemical properties of the systems. Bile salt mixed micelles are globally known as novel for drug delivery systems in living organism. The main purpose of the present method is to develop and examine the characterize mixed micelles [3] of anionic bile salts (Sodium deoxycholate and sodium cholate) and drug (Disprine or generic name Aspirin) in various temperatures.
\end{abstract}

Keywords: Bile Salts- Sodium Cholate, Sodium Deoxycholate, Conductometer, Disprine, cmc, Counter Ion Dissociation, Micelle

\section{Introduction}

Now a day's many applications (like in pharmaceutical, Detergency, Paint Industry etc) requires mixed surfactant systems, because it gives better performance and it is more effective even in small concentration than the pure surfactants systems [14, 12, 22 and 29]. The mixed surfactant system's behavior is synergistic; due to this, the total amount of surfactant required in any application get reduces [27], which in turn thus reduces both cost and environmental impact. The role of micellar catalysis in recent years has been no need to say its importance in different area such as pharmaceuticals, oil recovery industry, environmental as well as Nanotechnological system (Proceedings ICCE Indore 2005). The role of micellar catalysis may not be understood without the knowledge of its critical micelle concentration. This is the concentration where surfactant will work as micelle. Therefore, it is very interesting as well as important to know this factor very correctly and accurately. To begin with, it is useful to know the critical micelle concentration (cmc) of the surfactant used [22, 25]. Micelle formation is basically important for solublizing the drug substances which is determined by cmc based calculation. Solubilization of any active substances or drug is dependent on capacity and concentration of miceller system. The micellar formulations show are markable sensitivity to temperature. If the $\mathrm{cmc}$ is an important property of surfactants, as commented before, another relevant characteristic is the Krafft temperature. This can be defined as the minimum temperature at which surfactants form micelles. It is also explained in Reflection paper on the pharmaceutical development of intravenous medicinal products that active substances solubilised in micellar systems $[24,25]$. Below that temperature the formulation will fail because the surfactant remains in crystalline form, even in aqueous solution. On the other hand, as highlighted above, temperature can have a relevant effect on MAC (maximum additive concentration). Normally, micellar structure of drugs have executive charge of by pertaining to injection in to a vein, and are therefore it increases the dilution effects which increases the breaking of 
the micellar component and also its mobility towards targeted area and sufficiently minimize the risk of precipitation of the active substance in vivo [25]. The method and rate of administration may affect the disposition of drug substance and drug product excipients [25]. In the small intestine, coadministration of food and / or lipids leads to secretion of bile and digestive enzymes that produce a complex system of intestinal colloidal phases designed to facilitate the digestion and absorption of dietary lipids [34]. The increased concentration of bile and the presence of bile salt / dietary lipid mixed micelles can improve the wetting of poor soluble drugs and increase their effective solubility via solubilization [34]. Postprandial absorption may be improved by direct permeability enhancement or by solubilization that facilitates transport of lipophilic drugs across the aqueous diffusion layer. Intestinal lymphatic transport may also contribute to the absorption of highly lipophilic drugs [34].

Some researcher gives valuable knowledge related to this work e.g. Kabir - ud -Din, ate 1 (2010), give Mixed micellization behavior of antidepressant drug like amitriptyline hydrochloride with cationic surfactants. Tanushree et al; 2006 give The micellization behavior of an anionic Gemini surfactant, GA with non ionic surfactants $\mathrm{C}_{12}$ $\mathrm{E}_{8}$ and $\mathrm{C}_{12} \mathrm{E}_{5}$ in presence of $0.1 \mathrm{M} \mathrm{NaCl}$ at $298 \mathrm{~K}$ temperature, has been studied of drugs tensiometrically in pure and mixed states, and the related physicochemical parameters (cmc, $\gamma_{\mathrm{cmc}}, \Gamma_{\max }$, and $\mathrm{A}_{\min }$ ) have been evaluated. Tensiometric profile in the present report micellization tendency of Sodium Cholate (SC) and Sodium deoxycholate (SDC) with Disprine drug has been measured by conductometric methods. Application of bile salt in drug dissolution and its future scope is explain in Application of bile acids in drug formulation and delivery by (Maja et al; 2013 ) etc. In present work some other kind of drugs like Disprene, caffeine etc and its thermodynamical and interfacial parameter is calculated. Importance of this work is because 1 . Recently, bile acids have drawn much attention in the field of drug delivery due to the irability to act as a drug carrier system in the form of mixed micelles, bilosomes and chemical conjugates with drug. 2. Drugs that are slightly soluble in water may be solubilized with in bile salt micelles, in order to improve their absorption. In aqueous solution, bile acid anions self- associate to form simple micelles.

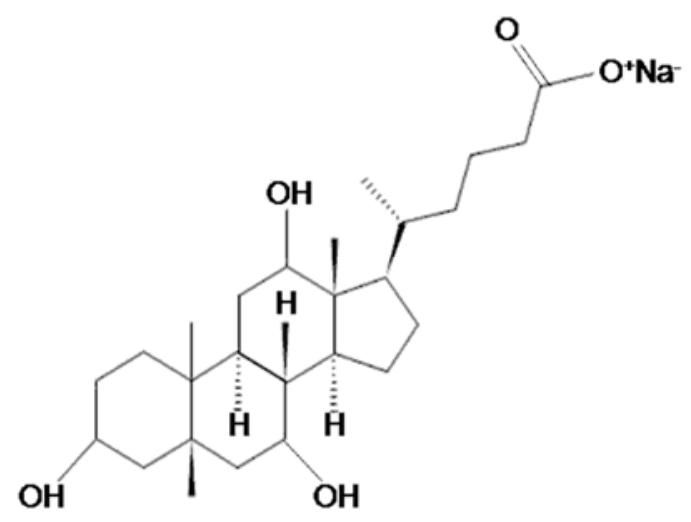

Fig. 1. SodiumCholate.

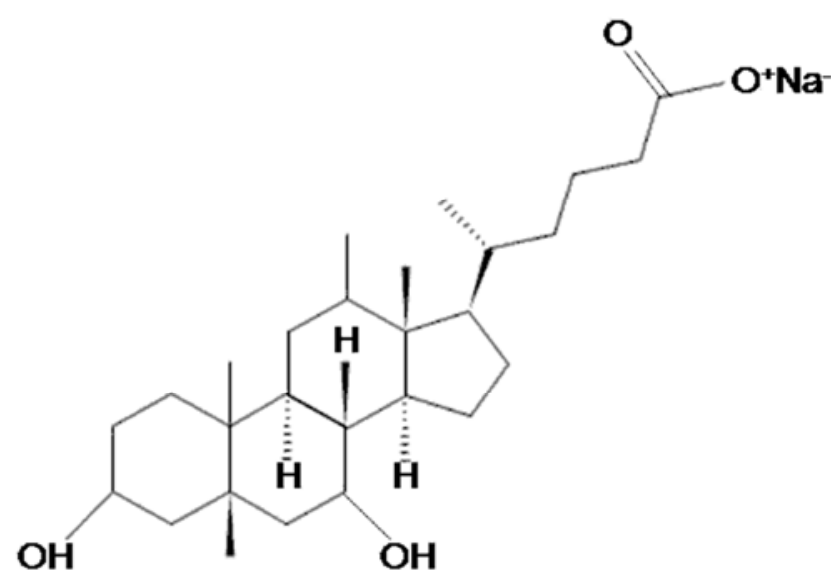

Fig. 2. Sodium deoxycholate.

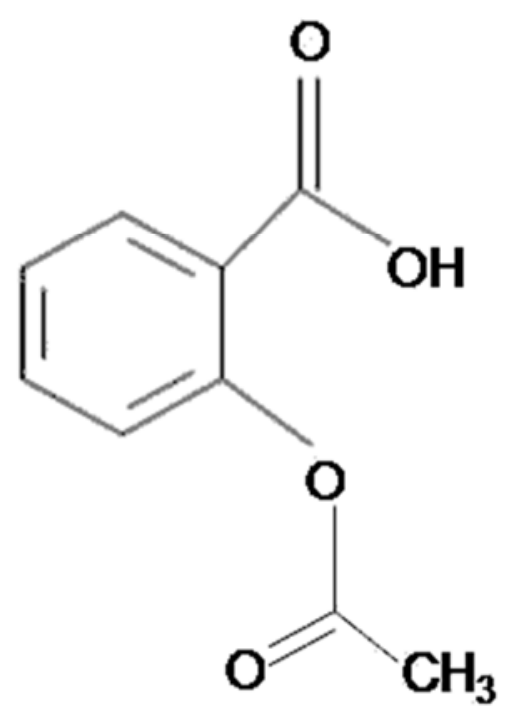

Fig. 3. Disprine.

\section{Experimental}

\subsection{Materials}

The bile surfactants sodium cholate and sodium deoxycholate used in the experiment was purchased (from LOBA Chemic) and Disprine (form Sigma). All the solutions were prepared in triple distilled water.

\subsection{Solution Preparation}

Solution where prepared employing triple distilled and deionized water. For the experimental work following solutions were prepared-

a. Stock solution $(0.1 \mathrm{~N}$ to $0.01 \mathrm{~N}$ of SC and SDC)

$0.1 \mathrm{M}$ solution of anionic surfactant solution i.e. Sodium cholate and Sodium deoxycholate in aqueous solvents.

b. Medium-25 $\mathrm{ml}$ of triple distilled water taken as the medium for the experiments.

c. Drug solution- $0.1 \mathrm{~N}$ solution of drugs solution i.e. Disprene. 


\section{Results and Discussion}

\subsection{Determination of Critical Micellization Concentration Value of Binary Mixtures}

Table 1. Experimentally obtained critical micelle concentrations of the Sodium deoxycholate with Disprine in various concentrations at room temperature.

\begin{tabular}{llll}
\hline concentration of SDC $(\mathbf{m M})$ & $\begin{array}{l}\text { Concentration of Disprine } \\
(\mathbf{m M})\end{array}$ & cmc (mM) & $\begin{array}{l}\boldsymbol{\alpha}(\text { Mole fraction of the more } \\
\text { hydrophobicsurfactantinthesolution) }\end{array}$ \\
\hline 0.1 & 0.1 & 0.05 & 0.192 \\
0.09 & 0.1 & 0.038 & 0.448 \\
0.08 & 0.1 & 0.0325 & 0.438 \\
0.07 & 0.1 & 0.04 & 0.6 \\
0.06 & 0.1 & 0.0266 & 1.28 \\
0.05 & 0.1 & 0.0187 & 0.2933 \\
0.04 & 0.1 & 0.0327 & 0.000225 \\
0.03 & 0.1 & 0.0216 & 0.0617 \\
0.02 & 0.1 & 0.0171 & 0.076 \\
0.01 & 0.1 & 0.016 & 0.053 \\
\hline
\end{tabular}

Table 2. Experimentally obtained critical micelle concentrations of the Sodium cholate with Disprine in various concentrations by conductometric method.

\begin{tabular}{llll}
\hline concentration of SC(mM) & $\begin{array}{l}\text { Concentration of Disprine } \\
(\mathbf{m M})\end{array}$ & cmc (mM) & $\begin{array}{l}\boldsymbol{\alpha} \text { (Mole fraction of the more hydrophobic } \\
\text { surfactant in the solution) }\end{array}$ \\
\hline 0.1 & 0.1 & 0.06 & 0.443 \\
0.09 & 0.1 & 0.056 & 0.77 \\
0.08 & 0.1 & 0.045 & 0.0204 \\
0.07 & 0.1 & 0.04 & 0.0326 \\
0.06 & 0.1 & 0.0314 & 0.0416 \\
0.05 & 0.1 & 0.036 & 0.135 \\
0.04 & 0.1 & 0.035 & 0.16 \\
0.03 & 0.1 & 0.0325 & 0.892 \\
0.02 & 0.1 & 0.0266 & 0.235 \\
0.01 & 0.1 & 0.0244 & 0.124 \\
\hline
\end{tabular}

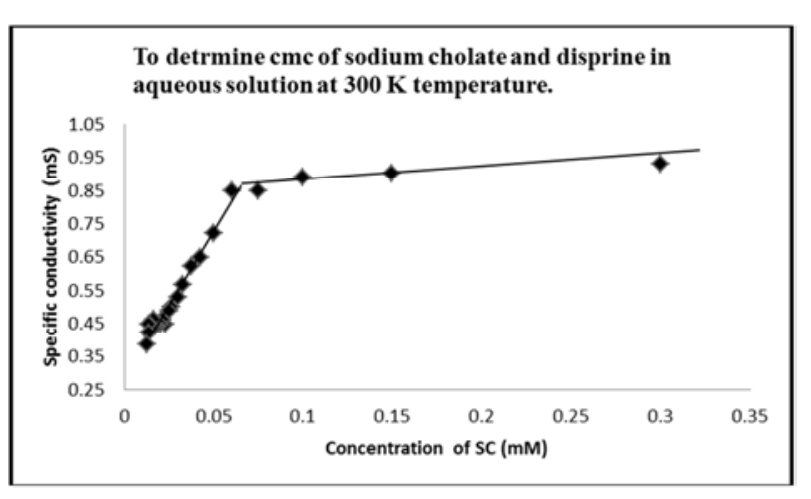

Fig. 4. Plot of conductance vs concentration of $S C(0.1 \mathrm{mM})$ and disprine $(0.1 \mathrm{mM})$ in aq. Solution at $300 \mathrm{~K}$.

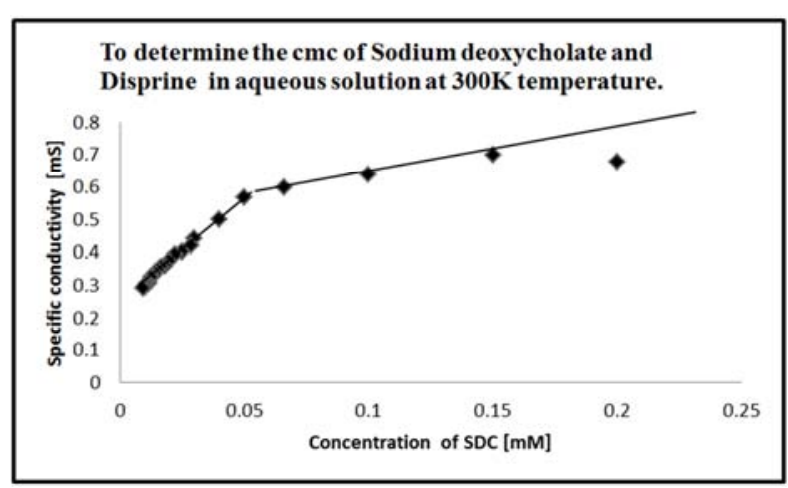

Fig. 5. Plot of conductance vs concentration of $S D C(0.1 \mathrm{mM})$ and disprine $(0.1 \mathrm{mM})$ in aq. Solution at $300 \mathrm{~K}$

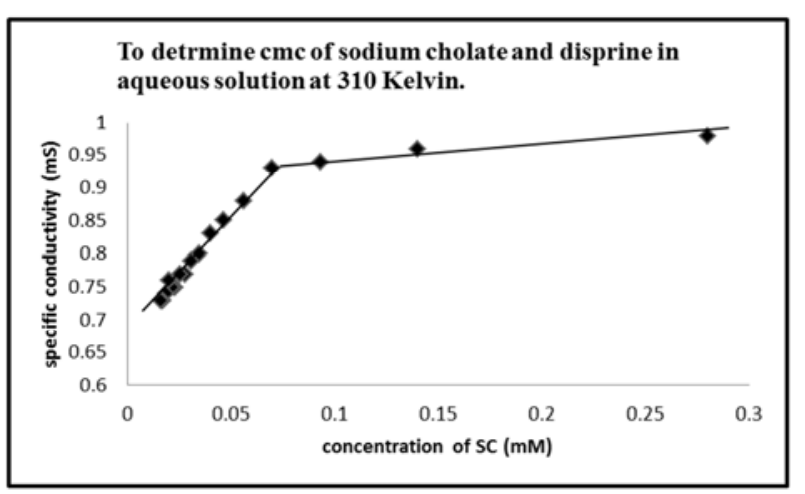

Fig. 6. Plot of conductance vs concentration of $S C(0.09 \mathrm{mM})$ and disprine $(0.1 \mathrm{mM})$ in aq. Solution at $310 \mathrm{~K}$.

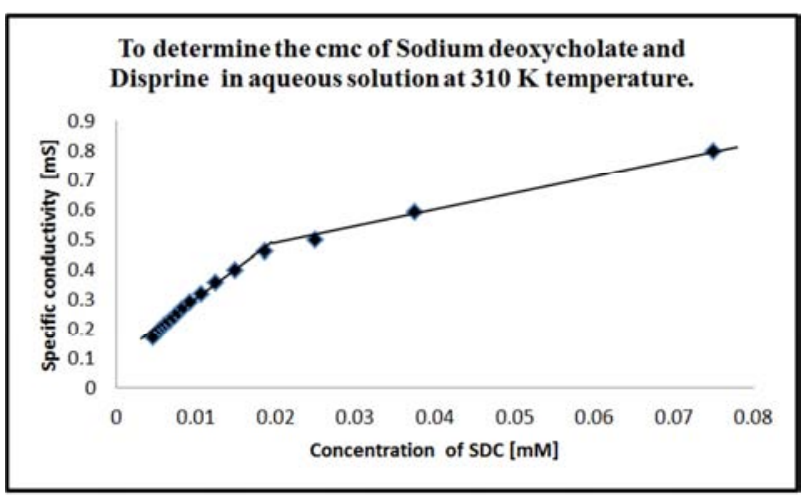

Fig. 7. Plot of conductance vs concentration of SDC (0.04 mM) and disprine $(0.1 \mathrm{mM})$ in aq. Solution at $310 \mathrm{~K}$. 


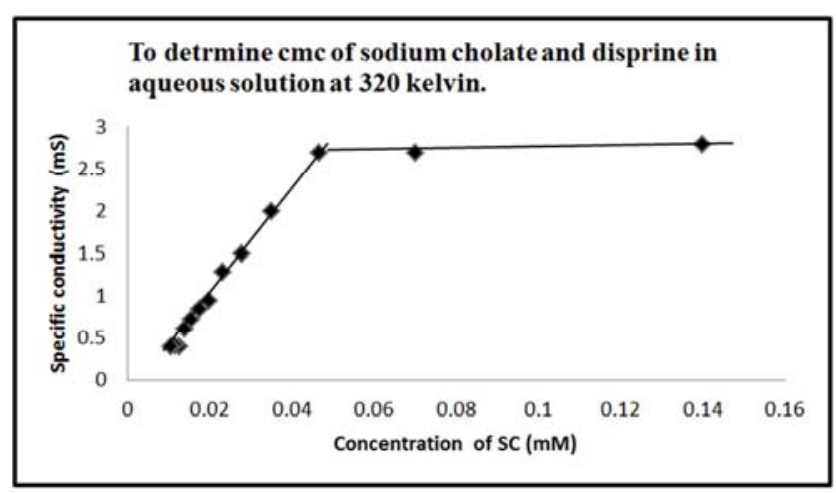

Fig. 8. Plot of conductance vs concentration of SC $(0.04 \mathrm{mM})$ and disprine $(0.1 \mathrm{mM})$ in aq. Solution at $320 \mathrm{~K}$.

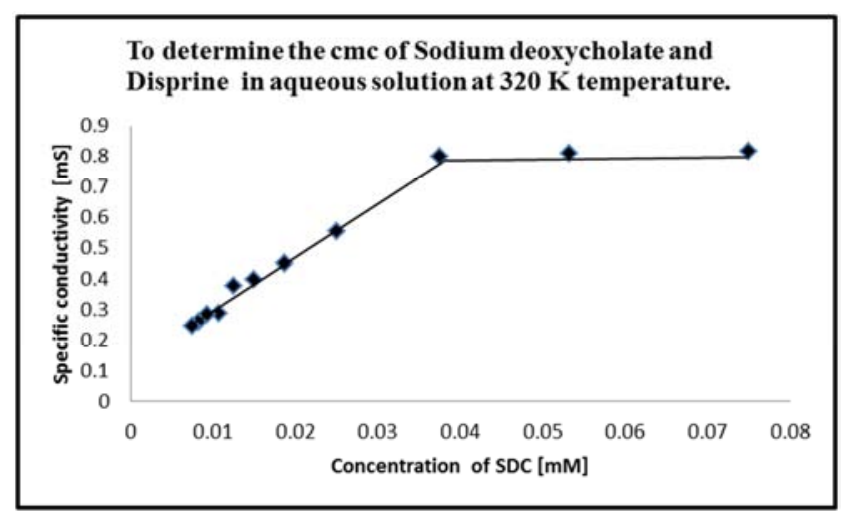

Fig. 9. Plot of conductance vs concentration of SDC $(0.05 \mathrm{mM})$ and disprine $(0.1 \mathrm{mM})$ in aq. Solution at $320 \mathrm{~K}$.

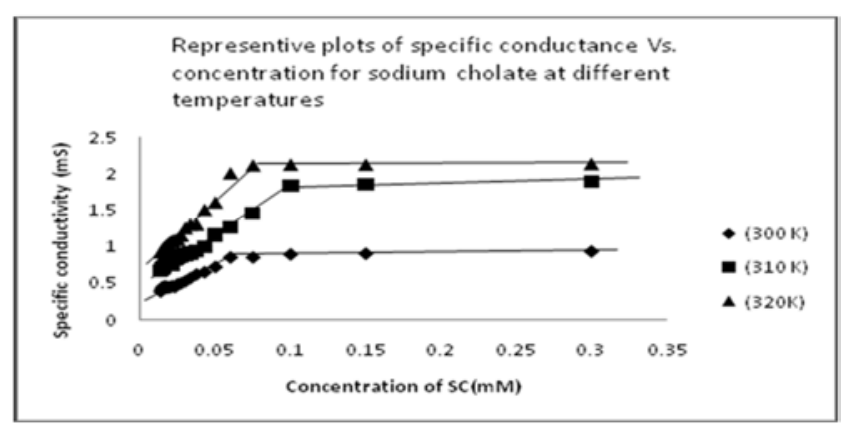

Fig. 10. Representive plot of specific conductance vs concentration of SC $(0.03 \mathrm{mM})$ and disprine $(0.1 \mathrm{mM})$ in aq. Solution at various temperatures.

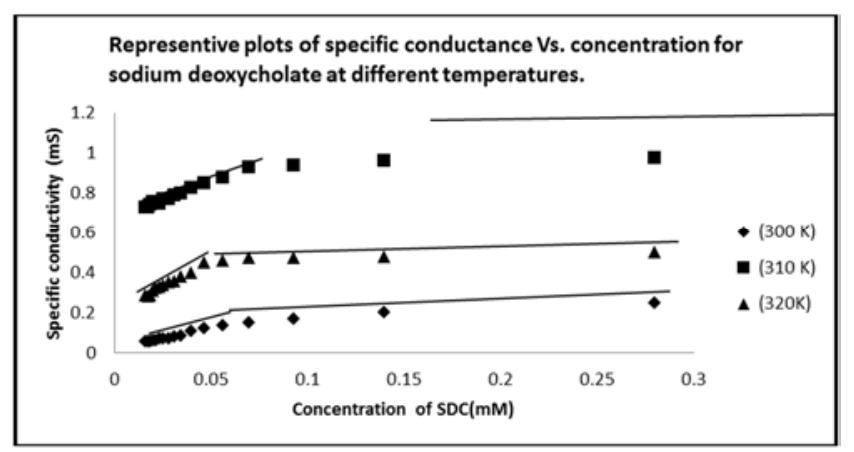

Fig. 11. Representive plot of specific conductance vs concentration of SDC $(0.09 \mathrm{mM})$ and disprine $(0.1 \mathrm{mM})$ in aq. Solution at various temperatures.

The CMC of the binary mixtures (Bile salt and Drugs) were studied using conductivity measurements, at different mole fractions and different temperature [3]. Prepared mixtures consisted of 0.1-1mole fractions of Sodium cholate and Sodium deoxycholate and 0.1 mole fraction of Disprine. Results are presented in Table 1 and 2.

The cmc values for individual non ionic surfactants and Disprine were obtained through conductometric measurements.

Table 3. Experimental critical micelle concentration of the individual surfactants.

\begin{tabular}{llll}
\hline Surfactants & SC $(\mathbf{m M})$ & SDC $(\mathbf{m M})$ & Disprine $(\mathbf{m M})$ \\
\hline $\mathrm{Cmc}^{\mathrm{ex}} / \mathrm{mM}$ & 12 & 6 & 0.977 \\
\hline
\end{tabular}

\subsection{Effect of Temperature on the Micellization Process}

Variation in temperature also affects the value of cmc. Generally the reason behind this fact is based on two terms-1. As the temperature increases the degree of hydration of the hydrophobic group decreases, which favors micellization; however, when temperature increases it destroy the structure of water molecule and surrounding of the hydrophobic group which is unfavorable to micellization and 2. Effect is predominant in the temperature range studied. [As referred in reference 30]. Sodium cholate (SC) and sodium deoxycholate (SDC) also shows various $\mathrm{cmc}$ values at different temperatures which have been explain in table 4-5. Result concluded that value of $\mathrm{cmc}$ of surfactants in aqueous solution increases with increase in temperature (from 300$320 \mathrm{~K}$, see figure 4-9) [16-17]. The studies presented here are very attractive from a pharmaceutical point of view. These findings offer important pharmacological options for the development of drugs dissolution by use bile salts. The purpose of this review is to provide a critical examination of the reported solubilization of drugs by bile salt micelles.

\subsection{Determination of the Physico-Chemical Parameters}

Mixed micellar media of bile salt and Disprine is calculated by various methods like Conductometric method, Drop counting stlagmometre etc. In present investigations, the physico-chemical parameters of the mixed micellar systems were calculated by using experimentally obtained cmc values $\left(\mathrm{cmc}^{\mathrm{ex}}\right)$ which calculated by above methods. Various thermodynamical parameters are calculated (like $\Delta \mathrm{S}_{\mathrm{m}}^{\mathrm{o}}, \Delta \mathrm{H}_{\mathrm{m}}^{\mathrm{o}}$ and $\left.\Delta \mathrm{G}_{\mathrm{m}}^{\mathrm{o}}\right)$ and physico-chemical parameters determined are: mole fraction of the more hydrophobic surfactant in the ideal mixed micelle system $\left(\mathrm{x}^{\mathrm{id}}\right)$, critical micelle concentration of ideal mixtures $\left(\mathrm{cmc}^{\text {id }}\right)$, $\beta$ parameterandthemolefractionofthemorehydrophobicsurfacta ntintherealmixedmicelle $\left(\mathrm{x}_{1}\right)$ by applying Clint, Motomura Rubingh theories.[2].

\subsection{Effect of Drugs on the Micellization Processs of Bile Salts}

Thermodynamics of micellization

All the thermodynamics parameters are temperature dependent. [30].

The (Gibbs free energy of micellization) $\Delta \mathrm{G}_{\mathrm{m}}^{\mathrm{o}}$ was calculated by using following equation- 


$$
\Delta \mathrm{G}_{\mathrm{m}}^{\mathrm{o}}=(2-\alpha) \mathrm{RT} \ln \mathrm{X}_{\mathrm{cmc}}
$$

The calculated value of parameter is shown in Table 6 and 7 at various temperature range. The $\Delta \mathrm{G}_{\mathrm{m}}^{\mathrm{o}}$ is decrease with increasing temperature, this value show that the micellization process is spontaneous in aqueous solution and magnitude of hydrophobic effect increases with increasing temperature. [30].

The (standard enthalpy of micellization) $\Delta \mathrm{H}_{\mathrm{m}}^{\mathrm{o}}$ can be derived by the Von't Hoff equation.

$$
\Delta \mathrm{H}_{\mathrm{m}}^{\mathrm{o}}=-(2-\alpha) \mathrm{RT}^{2}\left(\frac{d \ln X_{c m c}}{d T}\right)
$$

The result also shows that standard enthalpy of micellization is negative which indicates that the micelle formation process is exothermic which show strong interaction between drug and bile salts [30].

The (standard entropy of micellization) $\Delta \mathrm{S}_{\mathrm{m}}^{\mathrm{o}}$ was determined from the calculated values of $\Delta \mathrm{G}^{\mathrm{o}}{ }_{\mathrm{m}}$ and $\Delta \mathrm{H}_{\mathrm{m}}^{\mathrm{o}}$ by the help of following relationship

$$
\Delta \mathrm{S}_{\mathrm{m}}^{\mathrm{o}}=\left(\Delta \mathrm{H}_{\mathrm{m}}^{\mathrm{o}}-\Delta \mathrm{G}_{\mathrm{m}}^{\mathrm{o}}\right) / \mathrm{T}
$$

The $\Delta \mathrm{S}_{\mathrm{m}}^{\mathrm{o}}$ is always being positive which indicate that the process of micellization is entropy dominated over the micelle formation process. The positive value of $\Delta \mathrm{S}_{\mathrm{m}}^{\mathrm{o}}$ is due to the hydrophobic interaction between the surfactants and water molecule $[30,2]$. All values are presented in table 6 and 7.

\subsection{Development of Model}

The present study provides an insight in to the mechanism of interaction of bile salts with Disprine drugs. Based on the experimental findings it is possible to propose the concentration ranges involved with different stages of changes in the solubilisation of drugs by NaDC. The experiments showed that the concentration of a bile salt needed to bring about a certain change in the drugs is strongly dependent on the absolute concentrations of bile salt and not on their molar ratio. The bioavailability of orally administered drugs can be influenced by interacting with food constituent and by physico-chemical conditions in the upper gastrointestinal tract. Normally, bile salts enhance the transport of lipophilic drugs across mucosal membranes. Bile salts are able to form stable mixed micelles consisting of fatty acids and phospholipids. Table 4 and 5 shows that when surfactant (bile salt) added in the drug and distilled water solution, then the dissolution rate of the Disprine tablets increases. It concludes that even presence of small concentration of bile salts is very helpful for the dissolution of various drugs [32].

In method to observing the influence of the structure of drug on formation of mixed micelles [3] with SDC and SC, physicochemical values of micelles and mixed micelle were calculated by using experimental $\mathrm{cmc}$ values which is shown in table 6- 7 and table 4- 5.

$\mathrm{cmc}^{\mathrm{id}}, \mathrm{x}^{\mathrm{id}}, \mathrm{X}_{1}$ and the $\beta$ parameter all were calculated using following equation $[2,13]$.

The $\mathrm{cmc}^{\text {id }}$ parameter indicates non ideal behavior if it differs from $\mathrm{cmc}^{\mathrm{ex}}$. The values of $\mathrm{x}^{\mathrm{id}}$ and the $\mathrm{x}_{1}$ are used to calculate the $\beta$ parameter. According to Clint's theory, Critical micelle concentrations for ideal mixtures $\left(\mathrm{cmc}^{\text {id }}\right)$.

$$
\frac{1}{c m c^{i d}}=\sum_{i} \frac{\propto_{i}}{c m c_{i}}
$$

The $\mathrm{cmc}^{\mathrm{id}}$ values are presented and compared to the experimental $\mathrm{cmc}\left(\mathrm{cmc}^{\mathrm{ex}}\right)$ in Table 8 and 9 [2]. Deviation of the experimentally obtained $\mathrm{cmc}$ values from those calculated according to Clint's theory indicates nonideal behavior of examined surfactant mixtures and mutual interactions of the surfactants in the micelles. The mole fraction of the more hydrophobic surfactant in the ideal mixed micelle $\left(\mathrm{x}^{\mathrm{id}}\right)$, according to Motomura [2, 15], was calculated using the following relationship:

$$
X^{i d}=\frac{c m c_{2} \propto}{c m c_{2} \propto+c m c_{1}(1-\propto)}
$$

The $\mathrm{x}_{1}$ value was calculated by using following relation:

$$
1=\frac{X_{1}^{2} \ln \left(c m c^{e x} \propto / c m c_{1} X_{1}\right)}{\left(1-X_{1}\right)^{2} \ln \left[c m c^{e x}(1-\propto) / c m c_{2}\left(1-X_{1}\right)\right]}
$$

The $\mathrm{x}^{\text {id }}$ and the $X_{1}$ values for the mixed micelles are presented in Table 8 and 9. Further according to Rubingh [2, 14], $X_{1}$ value was used to calculate the $\beta$ interaction parameter, through the following equation:

$$
\beta=\frac{\ln \left(c m c^{e x} \propto / c m c_{1} X_{1}\right)}{(1-X)^{2}}
$$

B values explain the synergism or antagonism between two surfactants in mixed micelles. Its negative value indicate attractive interactions (synergism) between components of mixed micelles of drug and bile salt, The less negative value means the weaker synergistic interaction while positive values shows antagonistic interactions between surfactants in a mixture. Its value also shows the deviation between experimentally obtained $\left(\mathrm{cmc}^{\mathrm{ex}}\right)$ and calculated $\left(\mathrm{cmc}^{\mathrm{id}}\right) \mathrm{cmc}$ values [As referred in reference 2].

The activity coefficients of the two components, $f 1$ and $f 2$, are calculated using $X^{1}$ and $\beta$ valuesas:

$$
\begin{gathered}
f 1=\exp \left\{\beta\left(1-\mathrm{X}_{1}\right) 2\right\} \\
f 2=\exp \left\{\beta\left(\mathrm{X}_{1}\right) 2\right\}
\end{gathered}
$$

\section{Conclusion}

The CMC and $\alpha$ value of bile salts (SC and SDC) and drug (Disprine) mixtures were determined in aqueous solution. It was observed that both values were depending on concentration of mixed miceller media and various temperatures. It was observed that micellization tendency of SC and SDC decrease in the presence of mixed miceller media. The thermodynamic parameters are investigated. $\Delta \mathrm{G}_{\mathrm{m}}^{\mathrm{o}}$ is negative and becomes less negative with increase in concentration of mixed surfactants and solvent mixture. This suggest the micellization formation is becomes less 
spontaneous with increase in $g$ amount of surfactants and drug mixture in aqueous solution.

The entropy of micellization is positive indicated that the micellization process is somewhat entropy dominated.

Bile salts (sodium cholate and sodium deoxycholate) when interact with drug like Disprine, by conductometric method. The results of the study have been analyzed using Clint's, Rubingh's, and Motomura's theories for mixed binary systems [3]. The critical micelle concentration of the ideal mixed micelle, the mole fraction of the more hydrophobic surfactant in the ideal mixed micelle, the mole fraction of the more hydrophobic surfactant in the real mixed micelle, and the $\beta$ interaction parameter of the mixed micelles were calculated by using experimental values obtained [3]. It was concluded that increased synergistic interactions can be due to the larger number of hydrophilic groups present in the bile salts. Additionally, 7- oxo group of 7-oxo deoxy cholate enhance attractive interactions with selected co-surfactants more than 7-hydroxyl group of sodium cholate [3]. The presented studies here appear are very attractive from a pharmaceutical point of view. It is findings that it has very important pharmacological options for the development of drugs dissolution. The aim of this review is to discuss various chemical and pharmaceutical aspects of Bile salts and their potential applications in drug dissolution and delivery towards its targeted area.

Table 4. Critical micelle concentration and $\alpha$ value of various concentrations of Sodium Deoxycholate (SDC) and Disprine at different temperatures.

\begin{tabular}{|c|c|c|c|c|c|c|c|}
\hline \multicolumn{2}{|c|}{ SDC+Disprineconcentration } & \multicolumn{6}{|c|}{ Temperature(Kelvin) } \\
\hline \multirow{2}{*}{$\operatorname{SDC}(\mathbf{m M})$} & \multirow{2}{*}{ Disprine (mM) } & \multicolumn{2}{|c|}{300} & \multicolumn{2}{|l|}{310} & \multicolumn{2}{|l|}{320} \\
\hline & & CMC & $\alpha$ & CMC & $\alpha$ & CMC & $\alpha$ \\
\hline 0.1 & 0.1 & 0.05 & 0.192 & 0.066 & 0.75 & 0.066 & $?$ \\
\hline 0.09 & 0.1 & 0.03 & 0.448 & 0.0475 & 0.392 & 0.0633 & 0.137 \\
\hline 0.08 & 0.1 & 0.0325 & 0.438 & 0.0433 & 0.0908 & 0.052 & 0.137 \\
\hline 0.07 & 0.1 & 0.04 & 0.6 & 0.0566 & 1.25 & 0.071 & 0.013 \\
\hline 0.06 & 0.1 & 0.0266 & 1.28 & 0.032 & 0.919 & 0.04 & 0.281 \\
\hline 0.04 & 0.1 & 0.0327 & 0.0225 & 0.0054 & 0.357 & 0.0064 & 0.66 \\
\hline 0.03 & 0.1 & 0.0216 & 0.0617 & 0.0433 & 0.111 & 0.065 & $9.5 \times 10^{-3}$ \\
\hline 0.02 & 0.1 & 0.0171 & 0.076 & 0.024 & 0.07 & 0.03 & 0.0825 \\
\hline 0.01 & 0.1 & 0.016 & 0.053 & 0.0183 & 0.24 & 0.0171 & $1.16 \times 10^{-7}$ \\
\hline
\end{tabular}

Table 5. Critical micelle concentration and $\alpha$ value of various concentrations of Sodium Cholate (SC) and Disprine at different temperatures.

\begin{tabular}{|c|c|c|c|c|c|c|c|}
\hline \multicolumn{2}{|c|}{ SC+Disprineconcentration } & \multicolumn{6}{|c|}{ Temperature(Kelvin) } \\
\hline \multirow{2}{*}{$\mathrm{SC}(\mathrm{mM})$} & \multirow{2}{*}{ Disprine (mM) } & \multicolumn{2}{|c|}{300} & \multicolumn{2}{|l|}{310} & \multicolumn{2}{|l|}{320} \\
\hline & & CMC & $\alpha$ & CMC & $\alpha$ & CMC & $\boldsymbol{\alpha}$ \\
\hline 0.1 & 0.1 & 0.06 & 0.443 & 0.1 & 0.577 & 0.075 & 0.0634 \\
\hline 0.09 & 0.1 & 0.056 & 0.77 & 0.07 & 0.214 & 0.07 & 0.162 \\
\hline 0.08 & 0.1 & 0.045 & 0.0204 & 0.06 & 0.206 & 0.09 & 0.0325 \\
\hline 0.07 & 0.1 & 0.04 & 0.0326 & 0.048 & 0.133 & 0.06 & 0.0803 \\
\hline 0.06 & 0.1 & 0.0314 & 0.0416 & 0.0366 & 0.333 & 0.044 & 0.187 \\
\hline 0.04 & 0.1 & 0.035 & 0.16 & 0.035 & 0.292 & 0.035 & 0.0175 \\
\hline 0.03 & 0.1 & 0.0325 & 0.892 & 0.0216 & 0.192 & 0.0325 & 0.0416 \\
\hline 0.02 & 0.1 & 0.0266 & 0.235 & 0.0342 & 0.133 & 0.048 & 0.0625 \\
\hline 0.01 & 0.1 & 0.0244 & 0.124 & 0.0314 & 0.204 & 0.0366 & 0.187 \\
\hline
\end{tabular}

$\mathrm{CMC}$ at $300 \mathrm{~K}$ decreased but Values of the degree of Counter ion dissociation $(\alpha)$ can be determined by various methods, but is independent of the experimental method.

Table 6. Thermodynamic parameters for the micellization of various concentration of sodiumDeoxycholate (SDC) with Disprine [30].

\begin{tabular}{|c|c|c|c|c|c|c|c|c|c|c|c|}
\hline \multicolumn{4}{|c|}{ SDC+Disprine $(300 K)$} & \multicolumn{4}{|c|}{ SDC+Disprine(310K) } & \multicolumn{4}{|c|}{ SDC+Disprine(320K) } \\
\hline CMC & $\begin{array}{l}\Delta \mathbf{G}_{\mathrm{m}}^{\circ} \\
(\mathrm{kJ} / \mathrm{mole})\end{array}$ & $\begin{array}{l}\Delta \mathbf{H}_{\mathrm{m}}^{\circ} \\
(\mathrm{kJ} / \mathrm{mole})\end{array}$ & $\begin{array}{l}\Delta \mathbf{S}_{\mathrm{m}}^{\circ} \\
(\mathrm{kJ} / \mathrm{mole})\end{array}$ & CMC & $\begin{array}{l}\Delta \mathbf{G}_{\mathrm{m}}^{\circ} \\
(\mathrm{kJ} / \mathrm{mole})\end{array}$ & $\begin{array}{l}\Delta \mathbf{H}_{\mathrm{m}}^{\circ} \\
(\mathrm{kJ} / \mathrm{mole})\end{array}$ & $\begin{array}{l}\Delta \mathbf{S}_{\mathrm{m}}^{\circ} \\
(\mathrm{kJ} / \mathrm{mole})\end{array}$ & CMC & $\begin{array}{l}\Delta \mathbf{G}_{\mathrm{m}}^{\circ} \\
(\mathrm{kJ} / \mathrm{mole})\end{array}$ & $\begin{array}{l}\Delta \mathbf{H}_{\mathrm{m}}^{\circ} \\
(\mathrm{kJ} / \mathrm{mole})\end{array}$ & $\begin{array}{l}\Delta \mathbf{S}_{\mathrm{m}}^{\circ} \\
(\mathrm{kJ} / \mathrm{mole})\end{array}$ \\
\hline 0.05 & -62.76 & & & 0.066 & & & & 0.066 & & & \\
\hline 0.03 & -55.86 & -29.63 & 87.43 & 0.0475 & -48.36 & -32.78 & 50.2 & 0.0633 & -67.83 & -40.46 & 85.5 \\
\hline 0.0325 & -55.91 & -27.46 & 94.81 & 0.0433 & -57.88 & -35.84 & 71.07 & 0.052 & -68.80 & -37.27 & 98.52 \\
\hline 0.0425 & -49.18 & -26.87 & 74.36 & 0.0566 & -64.68 & -29.64 & 113.0 & 0.071 & -71.74 & -43.40 & 88.54 \\
\hline 0.0266 & -26.13 & -10.98 & 50.46 & 0.032 & -40.01 & -17.61 & 72.25 & 0.04 & -64.68 & -29.85 & 108.8 \\
\hline 0.0187 & -63.4 & -44.43 & 63.36 & 0.025 & -65.08 & -48.03 & 54.98 & 0.0375 & -75.47 & -59.13 & 51.06 \\
\hline 0.0327 & -71.5 & -18.46 & 17.6 & 0.0054 & -68.37 & -16.20 & 168.2 & 0.0064 & -42.50 & -14.08 & 88.8 \\
\hline 0.0216 & -73.0 & -79.89 & 22.93 & 0.0433 & -68.45 & -83.1 & 47.26 & 0.065 & -72.33 & -93.34 & 65.67 \\
\hline 0.076 & -71.9 & -40.46 & 104.9 & 0.024 & -72.9 & -43.34 & 95.3 & 0.03 & -73.62 & -45.88 & 86.68 \\
\hline 0.016 & -65.4 & -60.7 & 15.6 & 0.0183 & -70.4 & -51.2 & 61.93 & 0.0171 & -67.9 & -52.2 & 49.06 \\
\hline
\end{tabular}


Table 7. Thermodynamic parameters for the micellization of various concentration of sodium cholate (SC) with Disprine [30].

\begin{tabular}{|c|c|c|c|c|c|c|c|c|c|c|c|}
\hline \multicolumn{4}{|c|}{$\mathrm{SC}+$ Disprine $(300 \mathrm{~K})$} & \multicolumn{4}{|c|}{$\mathrm{SC}+\mathrm{Disprine}(310 \mathrm{~K})$} & \multicolumn{4}{|c|}{$\mathrm{SC}+$ Disprine $(320 \mathrm{~K})$} \\
\hline CMC & $\begin{array}{l}\Delta \mathbf{G}_{\mathrm{m}}^{\circ} \\
(\mathrm{kJ} / \mathrm{mole})\end{array}$ & $\begin{array}{l}\Delta \mathbf{H}_{\mathrm{m}}^{\circ} \\
(\mathrm{kJ} / \mathrm{mole})\end{array}$ & $\begin{array}{l}\Delta \mathbf{S}_{\mathrm{m}}^{\circ} \\
(\mathrm{kJ} / \mathrm{mole})\end{array}$ & СМС & $\begin{array}{l}\Delta \mathbf{G}_{\mathrm{m}}^{\circ} \\
(\mathrm{kJ} / \mathrm{mole})\end{array}$ & $\begin{array}{l}\Delta \mathbf{H}_{\mathrm{m}}^{\circ} \\
(\mathrm{kJ} / \mathrm{mole})\end{array}$ & $\begin{array}{l}\Delta \mathbf{S}_{\mathrm{m}}^{\circ} \\
(\mathrm{kJ} / \mathrm{mole})\end{array}$ & СМС & $\begin{array}{l}\Delta \mathbf{G}_{\mathrm{m}}^{\circ} \\
(\mathrm{kJ} / \mathrm{mole})\end{array}$ & $\begin{array}{l}\Delta \mathbf{H}_{\mathrm{m}}^{\circ} \\
(\mathrm{kJ} / \mathrm{mole})\end{array}$ & $\begin{array}{l}\Delta \mathbf{S}_{\mathrm{m}}^{\circ} \\
(\mathrm{kJ} / \mathrm{mole})\end{array}$ \\
\hline 0.06 & -53.35 & -13 & 134.5 & 0.1 & -48.51 & -12.68 & 115.56 & 0.075 & -69.63 & -18.28 & 160.45 \\
\hline 0.056 & -42.12 & -10.21 & 106.36 & 0.07 & -62.53 & -15.92 & 150.35 & 0.07 & -66.43 & -17.45 & 153.0 \\
\hline 0.045 & -62.83 & -49.57 & 54.18 & 0.06 & -63.52 & -49.67 & 365.1 & 0.09 & -69.79 & -58.05 & 36.68 \\
\hline 0.04 & -69.40 & -29.84 & 131.8 & 0.048 & -67.18 & -30.24 & 119.1 & 0.06 & -70.17 & -33.13 & 115.74 \\
\hline 0.0314 & -70.27 & -24.71 & 151.83 & 0.0366 & -61.15 & -22.46 & 124.8 & 0.044 & -67.76 & -26.03 & 130.38 \\
\hline 0.035 & -65.52 & -19.70 & 152.71 & 0.035 & -62.85 & -19.53 & 139.73 & 0.035 & -75.30 & -24.15 & 159.81 \\
\hline 0.0325 & -39.66 & 0 & 132.2 & 0.0216 & -68.78 & 0 & 221.8 & 0.0325 & -74.78 & 0 & 233.68 \\
\hline 0.0266 & -55.43 & -21.5 & 113 & 0.0342 & -68.81 & -44.02 & 79.94 & 0.048 & -71.97 & -48.68 & 72.78 \\
\hline
\end{tabular}

Table 8. Value of $\mathrm{cmc}^{i d} / \mathrm{mM}, C m c^{e x} / \mathrm{mM}, X^{i d} \& X_{1}$ and the $\beta$ of the mixed micelles of Disprine and anionic surfactants (SDC) at different mole fractions in aqueous solution [2].

\begin{tabular}{llllll}
\hline \multicolumn{6}{l}{ Disprine+SDC } \\
\hline $\boldsymbol{\alpha}$ & $\mathbf{C m c}^{\text {id }} / \mathbf{m M}$ & $\mathbf{C m c}^{\mathbf{e x}} / \mathbf{m M}$ & $\mathbf{X}^{\text {id }}$ & $\mathbf{X}_{\mathbf{1}}$ & $\boldsymbol{\beta}$ \\
\hline 0.192 & 1.18 & 0.05 & 0.037 & 1.712 & -7.52 \\
0.448 & 1.66 & 0.03 & 0.116 & 2.975 & -9.20 \\
0.438 & 1.63 & 0.0325 & 0.112 & 2.887 & -9.00 \\
0.6 & 0.045 & 0.04 & 0.196 & 3.483 & -10.47 \\
1.28 & -5.5 & 0.0266 & -2.912 & 0.51 & -0.29 \\
0.293 & 1.33 & 0.0187 & 0.063 & 2.522 & -9.02 \\
0.0225 & 0.997 & 0.0327 & $3.7 \times 10^{-3}$ & 0.873 & -8.93 \\
0.0617 & 1.035 & 0.0216 & 0.01 & 1.30 & -8.85 \\
0.076 & 1.05 & 0.0171 & 0.013 & 1.457 & -9.04 \\
0.058 & 1.026 & 0.016 & $9.03 \times 10^{-3}$ & 1.343 & -9.23 \\
\hline
\end{tabular}

Table 9. Value of $\mathrm{cmc}^{i d} / \mathrm{mM}, C m c^{e x} / \mathrm{mM}, X^{\text {id }} \& X_{1}$ and the $\beta$ of the mixed micelles of Disprine and anionic surfactants (SC) at different mole fractions in aqueous solution [2].

\begin{tabular}{llllll}
\hline \multicolumn{2}{l}{ Disprine+SC } & & & & \\
\hline $\boldsymbol{\alpha}$ & $\mathbf{C m c}^{\text {id }} / \mathbf{m M}$ & $\mathbf{C m c}^{\mathbf{e x}} / \mathbf{m M}$ & $\mathbf{X}^{\text {id }}$ & $\mathbf{X}_{\mathbf{1}}$ & $\boldsymbol{\beta}$ \\
\hline 0.443 & 1.55 & 0.06 & 0.114 & 2.10 & -8.73 \\
0.77 & 2.74 & 0.056 & 0.352 & 3.698 & -16.51 \\
0.0204 & 0.993 & 0.045 & $3.37 \times 10^{-3}$ & 0.657 & -9.11 \\
0.0326 & 1 & 0.04 & $5.45 \times 10^{-3}$ & 0.769 & -8.96 \\
0.0416 & 1.01 & 0.0314 & $7.01 \times 10^{-3}$ & 0.869 & -9.11 \\
0.135 & 1.01 & 0.036 & 0.024 & 1.263 & -8.44 \\
0.16 & 1.12 & 0.035 & 0.03 & 1.359 & -8.47 \\
0.892 & 3.8 & 0.0325 & 0.573 & 0.535 & -29.6 \\
0.235 & 1.15 & 0.0266 & 0.456 & 0.758 & -24.6 \\
0.124 & 1.05 & 0.0244 & 0.352 & 0.885 & -19.44 \\
\hline
\end{tabular}

\section{Note- Parameters for Thermodynamic}

$\Delta \mathrm{G}_{\mathrm{m}}^{\mathrm{o}}=$ Gibbs free energy of micellization,

$\Delta \mathrm{H}_{\mathrm{m}}^{\mathrm{o}}=$ Standard enthalpy of micelle formation

$\Delta \mathrm{S}_{\mathrm{m}}^{\mathrm{o}}=$ Standard entropy of micellization

$\mathrm{T}=$ Temperature

$\mathrm{R}=\mathrm{Gas}$ constant

$\mathrm{X}_{\mathrm{cmc}}=$ Critical micelle concentration in mole fraction unit.

$\mathrm{A}=$ Conter ion dissociation

\section{Parameters for Development of Model}

$\mathrm{cmc}^{\mathrm{id}}=$ Concentration of ideal mixtures

$\mathrm{cmc}^{\mathrm{ex}}=$ Experimentally obtained critical micelle concentration $\mathrm{x}^{\mathrm{id}}=$ Mole fraction of the more hydrophobic surfactant in the ideal mixed micelle,

$\mathrm{X}_{1}=$ Mole fraction of the more hydrophobic surfactant in the real mixed micelle

\section{$\mathrm{B}=$ Interaction parameter}

$\mathrm{cmc}_{1}=$ Experimentally obtained $\mathrm{cmc}$ of the more hydrophobic (anionic) surfactant (SDCandSC)

$\mathrm{cmc}_{2}=\mathrm{cmc}$ of Disprine drug

$\alpha=$ Mole fraction of the more hydrophobic surfactant in the solution.

$\alpha_{i}=$ Mole fraction of the more hydrophobic surfactant in the solution.

$\mathrm{Rub}=$ value obtained by Rubings theory

\section{Acknowledgment}

The author Shweta Singh, JRF NUP is grateful to Dr. Arun Arora, Principal, Bhilai Institute of Technology, Durg for providing laboratory facilities for this work. This project is partially supported by BRNS, poject no. - 36(4) / 14/ 90/2014-BRNS/36014/29-2016.

\section{References}

[1] D. M. Ćirin et al, (2012), Dodecyl sulfate-non ionic surfactant mixed micelles hem. Ind. 66 (1) 21-28.

[2] Dejan M. Cirin, Mihalj M. Posa, Veljko S. Krstonosic, MajaLj. Milanovic, (2012), Cconductometric study of Sodium dodecylsulfate- non- ionic Surfactants (Triton X-100, A tween 20 , Tween 60 , Tween 80 or Tween 85 ) mixed micelle in aqueous solution, Hem. Ind, 66 (1), 21-28.

[3] Dejan M. Cirin, Mihalj M. Posa, Veljko S., 2011, Interactions between selected bile salts and Triton X-100 or sodium lauryl ether sulfate, Chemistry Central Journal 5:89.

[4] G. Moodssac, A. Al-Wardian, K. Glennand R. Palepu, (2004), Can J Chem, 82, 1774.

[5] I. A. Khan, A. J. Khanam, M. S. Sheikh, Kabir -ud -Din, (2011), Influence of ionic and non ionic hydro tropeson micellar behaviour of a cationic Gemini surfactant but anediyl- 1, 4-bis (di methyl cetyl ammonium bromide), J. Colloid. Interface, 15; 359 (2): 467-73.

[6] J. Piret, A. Désormeaux, M. G. Bergeron, (2002), Sodium lauryl sulfate, a microbicide effective against enveloped and non enveloped viruses, Curr. Drug Targets 3, 17-30. 
[7] J. Piret, Lamontagne J, Bestman- Smith J, S. Roy, P. Gourde, A. Désormeaux, R. F. Omar, J. Juhász, M. G. Bergeron, (2000), In vitro and in vivo evaluations of sodium lauryl sulfate and dextran sulfate as micro bicides against herpes simplex and human immune deficiency viruses, 38 (1): 110.

[8] J. L. Palous, M. Turmine, P. Letellier, (1998), Mixtures of non- ionic and ionic surfactants: Determination of mixed micelle composition using cross- differentiation relations, J. Phys. Chem., B 102, 5886-5890.

[9] Kabir- ud- Din, Rub M A, Naqvi A Z, (2011), Aqueous amphiphilic drug (amitriptyline hydrochloride)-bile salt mixtures at different temperatures, Colloids Surf B Biointerfaces, 84 (2): 285-91.

[10] Kabir-ud-Din, Rub M A, Naqvi A Z, (2010), Mixed micellization of antidepressant drug amitriptyline hydrochloride with cationic surfactants, Colloids Surf B Biointerfaces, 80 (2): 206-12, E pub 2010 Jun 19.

[11] Kallol K Ghosh and Vidyacharan Baghel, (2008), Indian Journal of chemistry, Vol. 47A, 1230-1233.

[12] M. J. Rosen, D. Murphy, (1986), Synergism in binary mixtures of surfactants: V. Two- phase liquid-liquid systems at low surfactant concentrations, J. Colloid Interface Sci. 110, 224-236.

[13] M. Jahirul Islam, M. M. R. Choundri, S. M. F. Shahed, M. A. Subhan, (2009), Effect of some biologically important organic compounds on the micellar properties of sodium dodecyl sulphate, Proc. Pak. Acad. Sci. 46, 91-95.

[14] M. J. Rosen, B. Y. Zhu, (1986), Synergism in binary mixtures of surfactant: III. Betaine- containing systems, J. Colloid Interface Sci. 99, 427-434.

[15] M. N. Shala by, (2008), Synergistic behaviour of binary mixed micellar solution, J. Dispersion Sci. Technol. 29, 447-452.

[16] Das A K, Hajra A K, (1992), Critical micellar concentrations of palmitoyl dehydroxy acetone phosphate and 1- palmitoylrac- glycerol 3- phosphate, J Biol Chem, 267, 14, 9731.

[17] Mazer N A, (1985), Laser Light Scattering in Micellar systems in 'Dynamic Light Scattering: Applications' by $\mathrm{R}$ Pecora, Springer, 305-346.

[18] Mohammad Safi, (2013), Aggregation behavior of amphiphilic drug and bile salt mixtures at different compositions and temperatures, The Journal of Chemical Thermodynamics, 64: 28-39.

[19] Navas A., D1 az, Garc1 aF., Sa nchez, A. Garc1 a Pareja, (1998), Cholic acid behavior in water and organic solvent: study of normal and inverted aggregates, 142, 27-34

[20] Nighat Razvi, Saeed Ahmad Siddiqui and Lubna Ghazal Khan, (2005), The effect of surfactant on the dissolution rate of ibuprofen tablet sinti. Chern. Pharm. Med. J. Vol. 2 (1), pp. 213-216.

[21] O. López, M. Cócera, E. Wehrli, J. L. Parra, A. De La Maza,
(1999), Solubilization of liposomes by sodium dodecyl sulfate: new mechanism based on the direct formation of mixed micelles, Arch. Biochem. Biophys. 367, 153-160.

[22] Piszkichwicz D., (1977), Kinetics Study of Malachite Green Fading, J. Am. Chem. Soc, 99, 7695.

[23] Prajapati K. and Patel S., 2012, Micellization of Surfactants in Mixed Solvent of Different Polarity, Archives of Applied Science Research, 4 (1): 662-668.

[24] Reflection paper on the pharmaceutical development of intravenous medicinal products containing active substances solubilised in micellar systems, (05 March 2012), EMA/ CHMP/ QWP/ 799402/ 2011Compliance and Inspection.

[25] Reflection paper on the pharmaceutical development of intravenous medicinal products containing active substances solubilised in micellar systems (non-polymeric surfactants), 23 Sep 2010 EMA/ CHMP/ QWP/ 799402/ 2011Compliance and Inspection.

[26] Sar Santosh K. and Rathod Nutan, (2011), Mixed micelle formation between amino acid-based surfactants and phospholipids. Sci. 359, 467-473.

[27] Sandhiya Jatwani, Avtarchand Rana, Gurpreet Singh and Geeta Aggarwal, (2004), An over view on solubility enhancement techniques for poorly soluble drugs and solid dispersion as an eminent strategic approach, IJPSR (2012), vol. 3 , issue 04

[28] S. A. Baeurte, and J. Kroener, (2004), Modeling effective interactions of micellar aggregates of ionic, J Math Chem. 36: 409-421.

[29] Santanu Paria, (2006), The mixing behavior of $\mathrm{n}$ alkylpyridinium bromide- NP- mixed surfactant systems, Colloids of surface, 281, 1-3, 113-118.

[30] Shweta \& Santosh k Sar, (2014), Micellization of some bile salt in binary aqueous solvent mixture, $\mathrm{J}$ of surfactants \& Detergent, 17, 143-150.

[31] Tiwari S. and Ghosh K. K.; (2008), Micellization of cetyltributylphosphonium Bromide in some Binary Aqueous Solvents mixtures, Tenside Surf. Det., 45, 5.

[32] Saeed Ahmad Siddiqui, Nighat Razvi, and Lubna Ghazal Khan, 2005, the effect of surfactant on the dissolution rate of ibuprofen tablets, in ti. chern. pharm. med. j. vol. 2 (1), pp. 213-216.

[33] Sujeet kumar chatterjee and tulasi Prasad niraula, ajaya bhattarai et al (2013), effects of concentration, temperature and solvent composition on density and apparent molar volume of the binary mixtures of cationic-anionic surfactants in methanol- water mixed solvent media, springer plus, 2:280.

[34] Williamn. charman, Christopher J. H. Porter, Sabena Mithani, Jennifer B. Dressman, (1997), Physicochemical and Physiological Mechanisms for the Effects of Food on Drug Absorption: The Role of Lipids and $\mathrm{pH}$, Volume 86, Issue 3, Pages 269-282. 